\title{
VLF surface-impedance measurements for ice-depth mapping - an assessment of some commonly encountered interference effects
}

\author{
David V. Thiel, Daniel James and Peter Johnson \\ Radio Science Laboralory, Faculty of Science and Technology, Griffith University, Nathan, Queensland 4111, Australia
}

\begin{abstract}
The effects on very low-frequency surface-impedance measurements of lateral variations commonly found in ice environments have been measured and modelled numerically using the quasi-static two-dimensional boundary-element method. Results indicate that surface-impedance measurements made in the vicinity of crevasses oriented perpendicular to the plane of incidence, and those made in the vicinity of moraines and melt streams, can all show significant changes to the measured apparent resistivity. It is, therefore, misleading to use such measurements in the interpretation of ice depth.
\end{abstract}

\section{INTRODUCTION}

Since the first work with VLF surface-impedance measurements in ice-covered regions (Thiel, 1986), the technique has been employed in the Antarctic in the southern summers of 1988-89 (Thiel and Neal, 1989), 1991-92, 1993-94 and 1994 95. All work has been directed at extracting ice-depth information from these measurements. While simple two-layer (i.e. ice rock) inversion techniques have yielded data in line with ice radar and other geophysics, there have been some occasions when the data were somewhat variable. For this reason, a detailed study of the technique has been undertaken in an attempt to explain these local variations. In particular, the influences of changes in ice conditions and proximity to moraines have yielded electromagnetic scattering effects which must be removed before data inversion for ice-depth extraction is attempted. While these effects will be described in this paper, it is appropriate to review the basic theory upon which the technique is based.

\section{SURFACE-IMPEDANCE THEORY}

A vertically polarized radio wave incident upon the surface of the Earth induces a horizontal electric field component $E_{x}$ directed in the plane of incidence (Fig. 1). For a uniform half space, the ratio between this field component and the magnetic field component $H_{y}$ perpendicular to the plane of incidence, is called the surface impedance $Z_{\mathrm{s}}$. The surface impedance is dependent on the electrical properties of the half space and is given by the relation:

$$
Z_{\mathrm{s}}=E_{x} / H_{y}=(j \omega \mu /(\sigma+j \epsilon \omega))^{\frac{1}{2}}
$$

where $j=(-1)^{\frac{1}{2}}, \omega$ is the angular frequency of the radiation, $\mu$ is the magnetic permeability of the half space, $\sigma$ is the conductivity of the half space and $\epsilon$ is the dielectric constant of the half space.

If the Earth is horizontally layered, then $Z_{s}$ for the upper layer (assuming an infinite half space) is modified by a factor $Q$ (Wait, 1970), which is dependent on the depth of the layers and their electrical properties. For example if the Earth plane consists of a single layer of ice of thickness $h_{1}$ overlying rock of infinite depth, the surface impedance measured on the upper surface of the ice is given by

$$
Z_{\mathrm{s}}=Q_{1} Z_{1}
$$

where $Q_{1}=\left[Z_{2}+Z_{1} \tanh \left(u_{1} h_{1}\right)\right] /\left[Z_{1}+Z_{2} \tanh \left(u_{1} h_{1}\right)\right]$, $Z_{1}$ and $Z_{2}$ are the impedances for an infinite half space given by Equation (1), and $u_{1}$ is the complex propagation coeflicient of the electromagnetic wave in the upper medium.

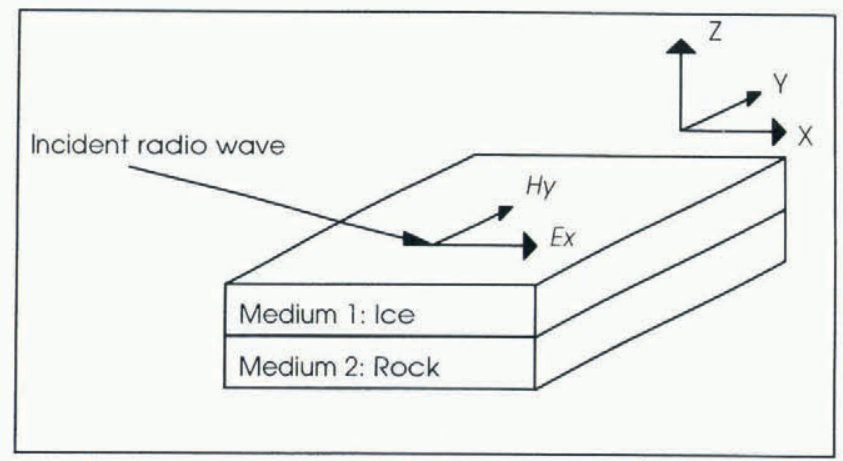

Fig. 1. Schematic representation of an ice laver on lop of rock. The plane of incidence lies in the XOZ plane. 
For a three-laver Earth structure, for example ice on sea water on rock, the impedance measured on the surface is given by Equation (2) where now

$$
\begin{aligned}
Q_{1} & =\left[Z_{\mathrm{s} 2}+Z_{1} \tanh \left(u_{1} h_{1}\right)\right] /\left[Z_{1}+Z_{\mathrm{s} 2} \tanh \left(u_{1} h_{1}\right)\right] \\
\text { and } \quad Z_{\mathrm{s} 2} & =Q_{2} Z_{2} \\
\text { and } \quad Q_{2} & =\left[Z_{3}+Z_{2} \tanh \left(u_{2} h_{2}\right)\right] /\left[Z_{2}+Z_{3} \tanh \left(u_{2} h_{2}\right)\right] .
\end{aligned}
$$

The same principle can be applied to any number of layers; however, in most circumstances in ice-covered regions, a three-layered model is sufficient to obtain bulk characteristics.

Commonly, the surface-impedance measurement is expressed in terms of an apparent resistivity $\rho_{\mathrm{a}}$ and a phase measurement. These are defined in the following way:

$$
\begin{aligned}
\rho_{\mathrm{a}} & =\left|Z_{\mathrm{s}}\right|^{2} / \omega \mu \\
\text { phase } & =\arg \left(Z_{\mathrm{s}}\right) .
\end{aligned}
$$

Based on this theory, VLF surface-impedance measurements have been used successfully to deduce ice thickness, ice conductivity and rock conductivity on temperate glaciers and in the Antarctic Thiel and Neal, 1989; Thiel, 1986).

In these papers, the effect of crevasses on the measurements was highlighted as a source of significant interference which may jeopardize reliable depth determinations. In this paper, however, the problem is examined in more detail both numerically using the boundary-element method and also experimentally. In a similar light, the scattering from other lateral changes in the ice surface is discussed.

\section{CREVASSE EFFECTS}

The effect of a crevasse on surface-impedance measurements is dependent on its orientation with respect to the plane of incidence of the radio signal. Figure 2 shows a

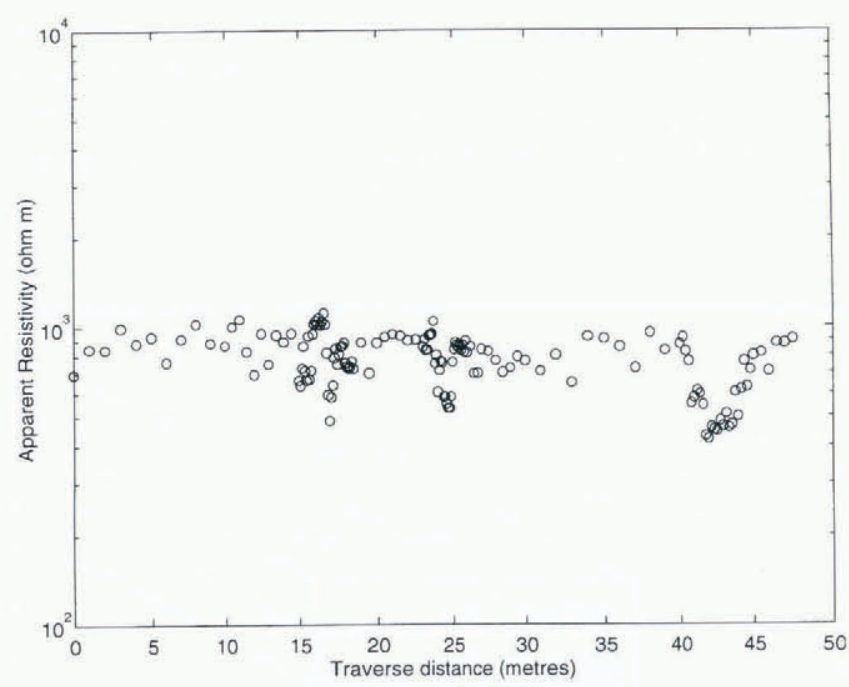

Fig. 2. Apparent resistivity measured across a series of four crevasses which lie almost parallel to the plane of incidence. The crevasses are localed at 16.6-17.1, 24.3-25.0, 40.841.8 and $42.443 .6 \mathrm{~m}$. surface-impedance traverse across a sequence of four crevasses which were all parallel to the plane of incidence. The crevasses were all at least $50 \mathrm{~m}$ deep and at least $0.5 \mathrm{~m}$ wide at the surface. The effect on the apparent resistivity measured across the path is less than $25 \%$ and only just outside the measurements variations along the traverse.

Figure 3 shows a traverse across a relatively small crevasse oriented perpendicular to the plane of incidence. The crevasse was approximately $10 \mathrm{~m}$ deep and $1 \mathrm{~m}$ wide at the surface. It is evident that the apparent resistivity has been significantly affected, changing by more than

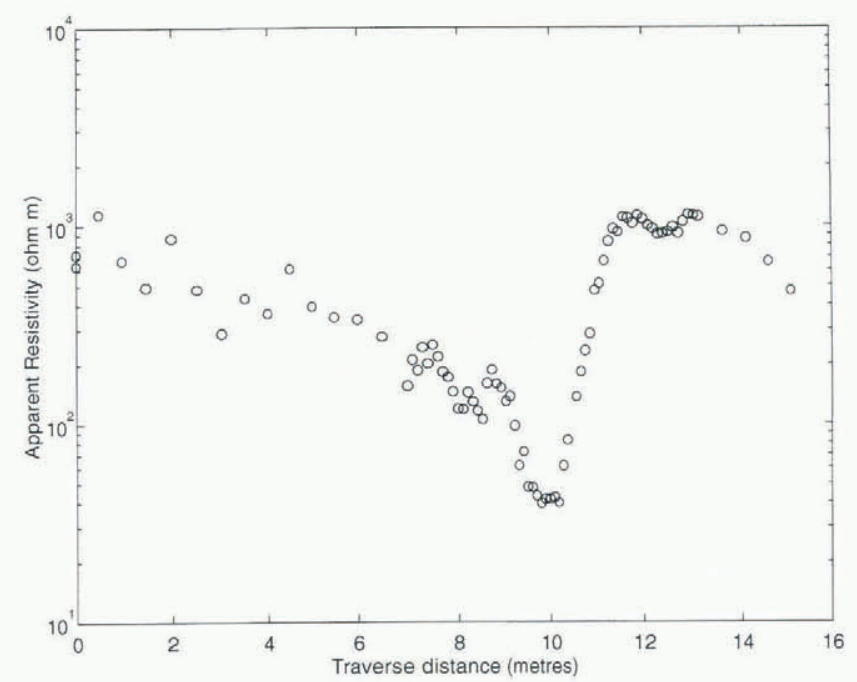

Fig. 3. Apparent resistivity measured across an isolated crevasse which is almost perpendicular to the plane of incidence. The crevasse is localed at $10 \mathrm{~m}$.

one order of magnitude. An electrostatic numerical model created using the boundary-element method Integrated Engineering Software, 1993 ) at a frequency of $20 \mathrm{kHz}$ is given in Figure 4. The model featured a $1 \mathrm{~m}$ wide air-

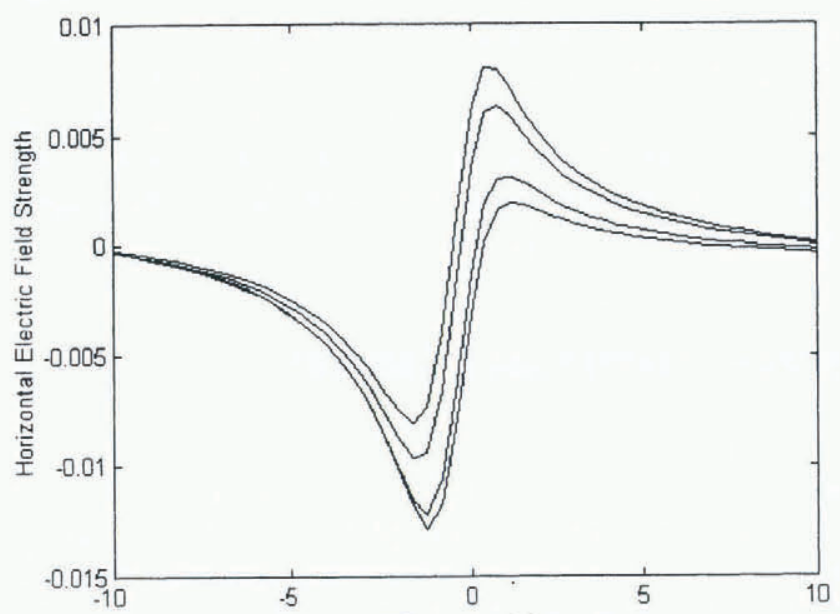

Fig. 4. Boundary-element method modelling of a $1 \mathrm{~m}$ wide crevasse in ice. The different curves relate to different orientations of the crevasse in the vertical direction $\left(90^{\circ}\right.$, $82.4^{\circ}, 75.1^{\circ}, 68.2^{\circ}$ and $61.9^{\circ}$ from top to bottom). The acule angle formed by the crevasse and the ice surface lies to the right of the zero position. 
filled crevasse in fresh-water ice. The depth of the crevasse was $150 \mathrm{~m}$, effectively infinite in terms of the model. The vertical orientation of the crevasse was varied through a number of angles. Results show a characteristic pattern which is influenced by the angle of the crevasse plane. Note that as the dip angle of the crevasse increases from vertical, the variation in the horizontal electric-field component becomes increasingly asymmetric. Note, also, that the side of the crevasse where the angle is more acute is the side where the anomaly in the horizontal electric field is less pronounced. In interpreting these numerical results, one must add a constant horizontal electric-field component which results in the total electric field remaining positive across the traverse. The apparent resistivity change across the path will be the square of the sum of this constant plus the anomaly curve. The effect on the apparent resistivity measurements will be determined by the value of the constant, which is a measure of the unperturbed electric field.

Clearly, if the vertical plane of the crevasse is perpendicular to the plane of incidence, the horizontal electric field is disrupted significantly. However, when the crevasse is almost parallel to the plane of incidence, the effect is often quite small. The automatic inversion of surface-impedance data using simple multi-laver models will not yicld satisfactory ice-depth results in the vicinity of crevasses which are oriented in a direction which is close to perpendicular to the plane of incidence.

\section{MELT-STREAM EFFECTS}

A travese was conducted across a surface melt stream which was approximately $1 \mathrm{~m}$ wide and $1 \mathrm{~m}$ deep. The stream was oriented almost perpendicular to the plane of incidence. Measured results are given in Figure 5. It is clear that this stream has an effect on the apparent resistivity but the magnitude of the change is relatively small, approximately a factor of 2. This is not unexpected given the small size of the feature. A numerical model of a stream of $1 \mathrm{~m}$ by $1 \mathrm{~m}$ square cross-section in ice yields a

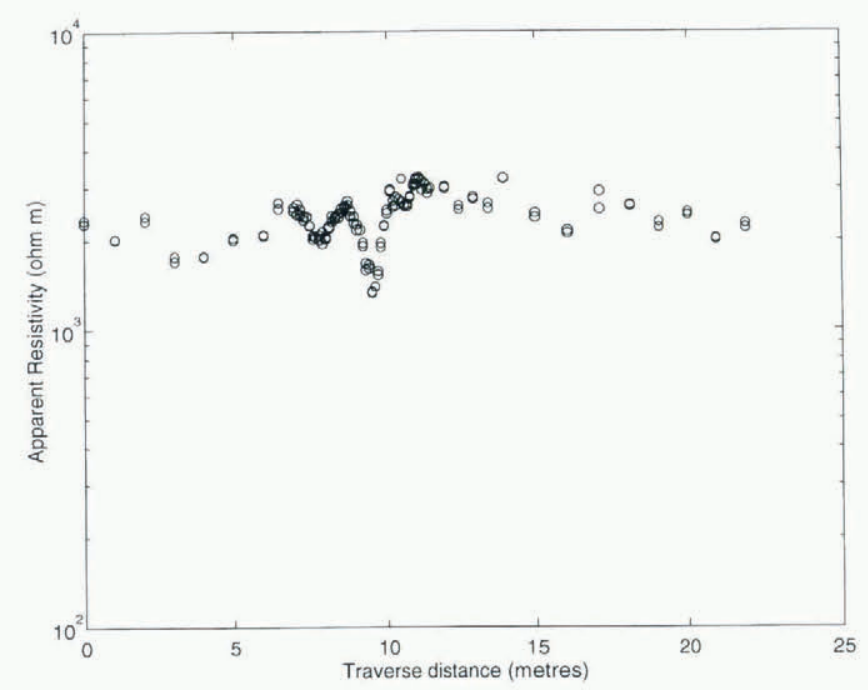

Fig. 5. Apparent resistivily measured across a $1 \mathrm{~m}$ wide mellwater stream in ice. The stream is located al position $9.6-10.3 \mathrm{~m}$. result similar to the effect of an orthogonal crevasse see Fig. 6).

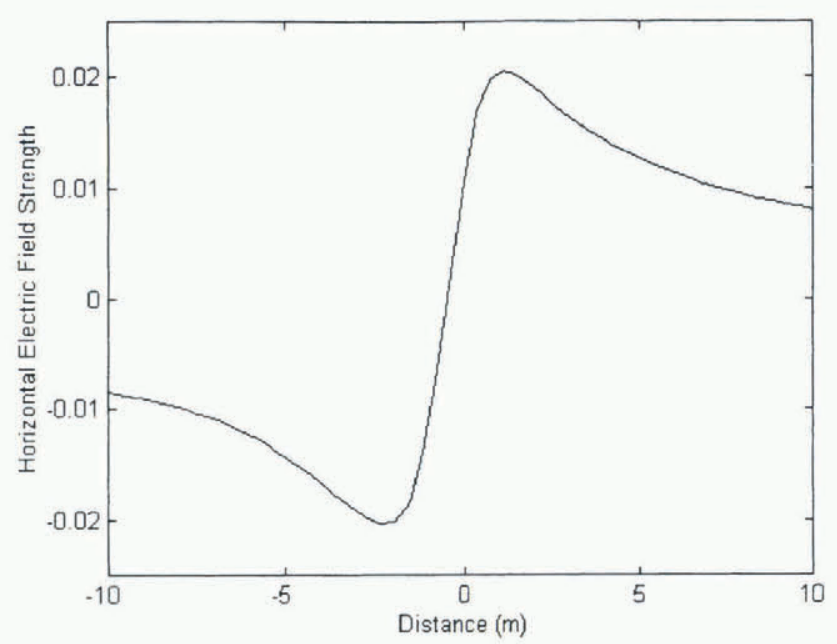

Fig. 6. Boundary-element method model of a melt stream having dimensions of $1 \mathrm{~m}$ by $1 \mathrm{~m}$.

\section{MORAINE EFFECTS}

While the effects of the moraine at Jack's Donga near Casey Station, Antarctica) were reported earlier Thiel and Neal, 1989), further measurements were made in the vicinity of these moraines. In particular, the effects of non-alignment of the instrument with the transmitter were assessed. At three different locations $-100 \mathrm{~m}$ below the moraine, $20 \mathrm{~m}$ above and $500 \mathrm{~m}$ above - both the electric and magnetic fields were measured as a function of angle measured in the horizontal plane. The moraine is oriented at approximately $20^{\circ}$ from the plane of incidence. The raw data were analysed by fitting a cosine function to each field component from each data set independently. The fitting routine minimized the least-squares error between the fit and the raw data. The angular displacement between the electric- and magneticfield components is given in Table 1.

The apparent resistivity derived from two of these data sets $(100 \mathrm{~m}$ and $+20 \mathrm{~m})$ has been plotted in Figure 7 as a function of angle. Note that, while there is always some variation in the measured surface impedance, at very low signal levels due to the non-zero signal-to-noise

Table 1. Angular displacement (relative 10 90') between the electric-and magnetic-field components measured in the vicinity of the triple-banded moraine at Jack's Donga (see lexl)

Location Angular displacement

m

$\begin{array}{ll}-100 & 1.3 \\ +20 & 8.9 \\ +500 & 0.2\end{array}$




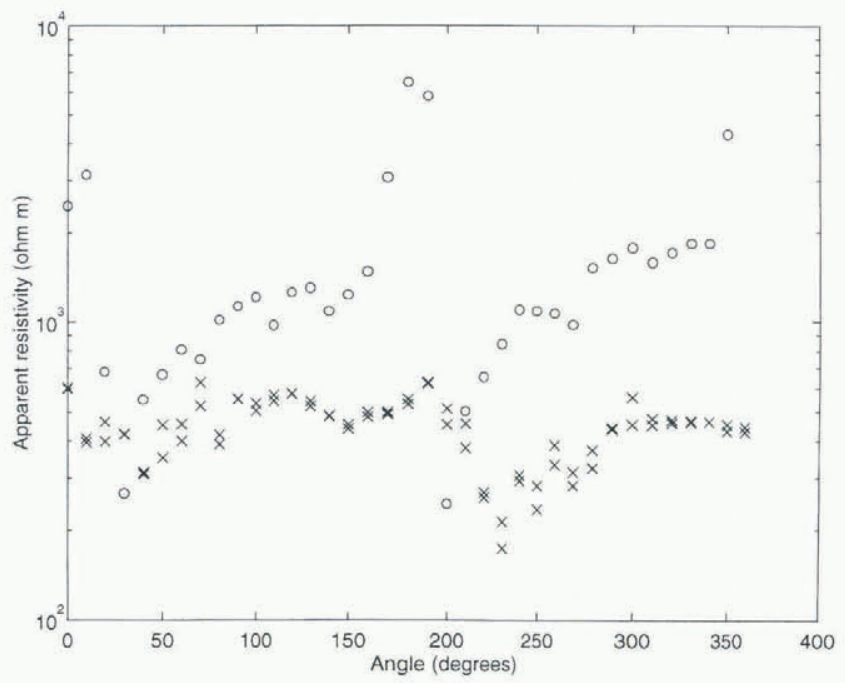

Fig. 7. Apparent resistivity measured as a function of bearing angle for two different locations in the vicinity of Jack's Donga. The large-variations measurements (circles) were laken $20 \mathrm{~m}$ from the moraines where the $\mathrm{E}$ and 11 fields are not orthogonal by 8.9. The other sel of measurements (crosses) were made $500 \mathrm{~m}$ from the moraine.

ratio of the instrument, when the two fields are significantly displaced in this case by approximately $9^{\circ}$ this angular dependence becomes significant. In Figure 7 , the variation in apparent resistivity is greater than a factor of 35. Figure 8 illustrates the variation in apparent resistivity calculated from the misalignment of $\mathrm{E}$ and $\mathrm{H}$ fields for these two angles, i.e. $1.3^{\circ}$ and $8.9^{\circ}$. The correct value for the surface impedance is found in the plane of incidence only. This phenomenon has been previously reported for the case of a uniform anisotropic half space (Thiel, 1984). Thus, measurements in the vicinity of scattering sources like the surface moraine cannot be used in inversion methods which assume stratified media only. This effect is also likely to be found in the vicinity of buried objects and surface vehicles.

\section{CONCLUSIONS}

While a number of lateral changes in ice conditions have been measured and analysed, it must be emphasized that the use of surface impedance as an ice-depth mapping tool has yielded satisfactory results over shallow ice regions. It is clear from this study, however, that where such features exist, these data should be removed from the data set

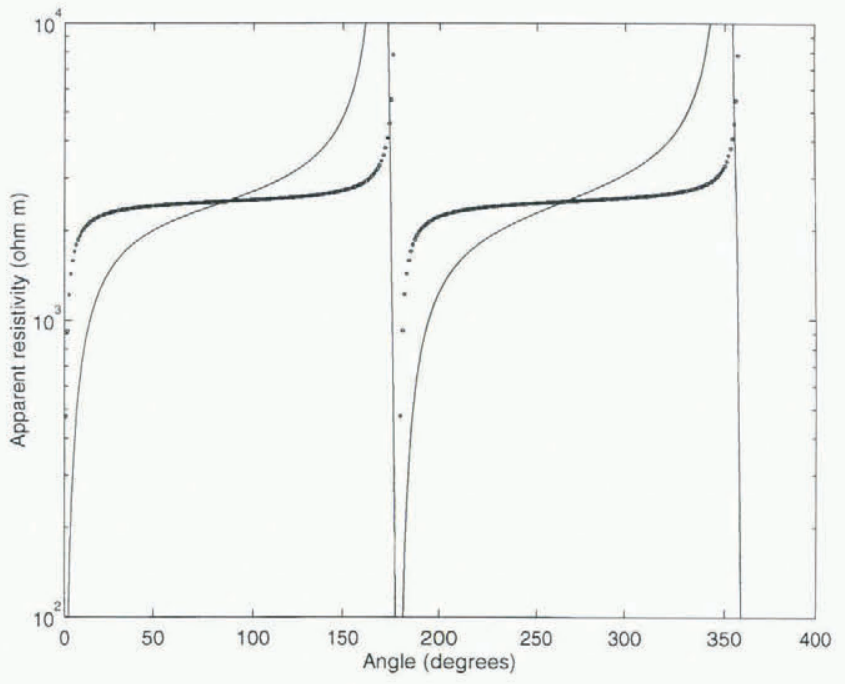

Fig. 8. The calculaled change in apparent resistivity due 10 a misalignment in the $E$ and $H$ fields for two angular separations: $1.3^{\circ}$ (heavy line) and $8.9^{\circ}$ (light line). Note that the true apparent resistivity is measured in the plane of incidence which in this case is at $90^{\circ}$.

before standard inversion routines are implemented. These scattering effects can be used in the mapping of surface and sub-surface features, such as cavities, melt streams and metallic objects, in ice-covered regions.

\section{ACKNOWLEDGEMENTS}

The research was supported by a grant from the Australian Scientific Antarctic Council. Expeditions to the Antarctic were supported by the Australian National Antarctic Research Expeditions. This paper was written partly while D.V.T. was visiting the Electromagnetic Communications Laboratory at the University of Illinois. The hospitality of Professor R. Mittra and colleagues was greatly appreciated.

\section{REFERENCES}

Integrated Engineering Software. 1993. Electro. Winnipeg, Integrated kngineering Software.

Thiel, D. V. 1984. One dimensional surface impedance measurements made above an anisotropic Earth. Expl. Geophys., 15, 43-46.

Thiel, D. V. 1986. A preliminary assessment of glacial ice profiling using VI.F surface-impedance measurements. J. Glaciol., $32112,376382$.

Thiel, D. V. and F. Neall. 1989. VLF surface-impedance measurements for ice-depth mapping in the Antarctic. J. Glaciol., 35 120), 197-200.

Wait. J.R. 1970. Electromagnetic waves in stratified media. Second edition. Oxford, ete., Pergamon Press. 